\title{
Curriculum 2000: a broader view of $A$ Levels?
}

\author{
Mark Priestley \\ Institute of Education \\ University of Stirling \\ Stirling FK9 4LA
}

\section{INTRODUCTION}

In England Curriculum 2000 has been the cause of considerable controversy since it was first conceived. It has been criticised for being structurally flawed and for its failure to overhaul A Levels (e.g. Hodgson and Spours 2001). Furthermore it has been plagued with high profile problems of implementation; in particular, examinations for both of its first two years have been marred by problems, the latter year's contributing to the downfall of the then Secretary of State for Education in 2002.

The initiative can be represented in many ways as a watershed in the development of the post-sixteen school curriculum in England. It is clear that it is the first substantial, and arguably successful attempt to reform provision at the level of Sixth Form since the inception of A Levels in 1951. Within the turbulent waters of education, stirred by seemingly continual change since the 1980s, very little has remained untouched. Indeed, Ball (1999), went so far as to state that A Level examinations may be the sole case of such continuity.

This is not to say that Sixth Form provision in general has not been subject to change over the last fifty years. The 1980s in particular witnessed a succession of what Young (1998) has termed incremental changes as factors such as increasing participation in post-sixteen education began to expose the inadequacies of existing provision. The development of internal assessment practices, modular syllabi and the introduction of alternative tracks (GNVQ and NVQ) are good examples of such 
change to provision at this level. Nevertheless, the 'gold standard' of the A Level has seemed to be immune to more fundamental structural change. Notwithstanding the apparently narrow nature of A Level study, particularly when compared with European systems (Hodgson and Spours 1996), its association with high academic standards and its selection functions have shielded it from reform. These factors have been associated with the very great support that $A$ Level has attracted within the elites of the Conservative administrations between 1979 and 1997, despite the increasingly hard to ignore evidence that this system of qualifications only benefited the students traditionally seen as the highest achievers (the $30 \%$ of students who gained A Levels), and in fact left up to $30 \%$ with no qualification at the end of their Sixth Form study. Lawton (1994: 136) described the:

long-standing desire (of the Tories) to hang onto the A Level failure system when educationists and industrialists have for 20 years been pleading for a broader curriculum and more integrated approach to education from 16-19.

The years of Conservative administration were thus characterised in Schon's (1971) terms by a 'dynamic conservatism'. This was manifested through resistance to attempts to reform A Levels structurally, notably the rejection of the Higginson Report (1988), and a reaction against practitioner initiated incremental reforms such as modular syllabi (Young, 1998), It is notable that when a Conservative government finally initiated the Dearing (1996) review of 16-19 provision, following pressures caused by increasing participation, and the manifest shortcomings of the three track system that had been instituted by the 1991 White Paper, Education and Training for the $21^{\text {st }}$ Century (DfE 1991), Dearing's brief actually precluded structural overhaul of A Levels (Hodgson and Spours 1997). As Young and Leney (1996: 50) have pointed 
out, Dearing was concerned not with how 'A Levels might be broadened, but how $A$ Level students might broaden their curriculum'.

Following the election of a Labour government in 1997, the consultation paper, Qualifying for Success (DfEE 1997), was published. This proposed a number of reforms that built upon the Dearing (1996) recommendations, and which were largely welcomed within education circles (Hodgson and Spours 2000) because they went some way to addressing the concerns of the groups identified by Lawton (1994); in particular the paper proposed broadening the Sixth Form curriculum by enabling students to take a greater range of subjects. This was to be largely achieved through the integration of key skills into A Level study, and through facilitating mix-andmatch choices (e.g. academic/vocational, science/arts). It also expressed a desire to promote access and a commitment to lifelong learning, through the provision of clear and coherent routes into higher education, and had a clear goal to improve 'levels of participation, retention and achievement' (DfEE 1997: 6) amongst young people.

Nevertheless, one should be cautious as seeing the proposals, which eventually came to fruition in Curriculum 2000 (QCA 1999), as representing fundamental structural change. While the reforms were represented by the government as being a 'move away from the damaging cycle of constant and piecemeal change that has bedevilled our qualifications systems for the past few years' (DfEE 1997: 5), and a structure for 'broader but coherent programmes of study' (ibid: 6), this is not the whole picture. For example, A Levels, in a modified form, were to remain as the main lynchpin of the new qualifications framework, as stated in Qualifying for Success (DfEE 1997: 9):

This government is committed to GCE A Levels. A Levels allow young people to acquire a high level of knowledge and understanding in the subjects and academic disciplines they cover. 
A number of issues concerning this important initiative are worthy of analysis. There is a range of implementation issues, many of which have been well publicised, including the impact of the reforms on schools, teachers and students, and most recently the grading crisis of 2002, when last minute adjustment to grade boundaries led to a media furore and a large scale regrading of examination scripts. Another theme concerns the philosophies underlying Curriculum 2000, as exemplified, for instance, in the debate over whether to retain A Levels in modified form, or to replace them a unified baccalaureate style qualifications framework. The purpose of this paper is to draw from both of these areas to some degree, in determining whether Curriculum 2000 has succeeded in one of its stated aims, that of increasing the breadth of provision. I have resisted the temptation to dwell at length on the crisis that blew up following the summer examinations of 2002, and which ultimately led to the resignation of the Secretary of State, Estelle Morris; these are interesting issues which throw the whole initiative into stark relief, but which ultimately relate to assessment rather than the issue which concerns this paper, that of breadth in provision.

The paper will examine the context for reform, before moving on to evaluate whether Curriculum 2000 has succeeded in broadening the Sixth Form curriculum. In doing this, it will draw upon the findings of existing research projects such as the IoE/Nuffield study (Hodgson and Spours 2000; Spours et al 2000; Savory et al 2001; Hodgson et al 2001; Hodgson and Spours 2001) and the Hargreaves reports (Hargreaves 2001a; 2001b). I will also bring to light some of the findings of my own research project, The impact of Curriculum 2000 in schools. This study, which will be described later in the paper, has produced some interesting preliminary findings that supplement those of the above named researchers.

\section{THE CONTEXT FOR REFORM}


The Curriculum 2000 reforms should be viewed against a complex backdrop of global and national educational change. Education systems worldwide have been subject over the last decade or so to what Hargreaves (1994: 6) has described as 'rampant and remorseless' changes. The process of change witnessed in England and Wales in the related fields of assessment and curriculum since the 1988 Education Reform Act has been typical of these global trends.

I have argued elsewhere (Priestley 2002) that these changes are part of, and at least in part subject to the phenomenon known as globalization, and occur as states both respond to and react against forces of change. Education, and specifically, in the context of this paper, the school curriculum, can be viewed as an arena, which largely remains under state control in an era of accelerating globalization (Young 1998; Green 1999; Hodgson and Spours 1999); as such it has the potential to be used as a policy lever, which may help ensure future economic prosperity, when more traditional means of economic sovereignty are being ceded to global and regional agencies such as the IMF and the European Community (Reich 1991; Reich 1992; Dale 1999).

Such interpretations may be disputed, but nevertheless it is difficult to deny that education is seen by governments themselves as having an important part to play in maintaining international competitiveness. This was clearly evident in the internecine struggles between the industrial trainers and the cultural restorationists that underpinned the development of policy during the Conservative years (Ball 1990; Lawton 1994). It is also clearly expressed in the words of the policy writers of the Labour Party (1996: 2):

Education is the key to economic success, social cohesion and active citizenship. Our future economic prosperity depends upon the skills and 
abilities of our people. In a rapidly changing, technologically advanced and increasingly competitive global economy, Britain needs a worldclass system of education and training. The regular updating of skills and knowledge has become essential to maintaining and enhancing productivity in the workplace.

This emphasis on economic imperatives continues to be evident in more recent publications (e.g. DfES 2002), and goes some way towards explaining the push to reform the A Level curriculum.

Of course this instrumental thrust is not the whole story. Such perspectives help to explain the increasing dirigiste interest in education by British governments of all political persuasions over the last couple of decades, but we also need to bear in mind that 'multi-causality, pluralistic conflict, administrative complexity and historical inertia‘ (Hargreaves 1983: 49) all have a role to play in the policy making and implementation processes. Nor is the hegemony of dominant interests the sole factor, although this helps to explain the persistence of A Levels. As Ball (1990: 3) stated,

education policy is not simply a direct response to dominant interests, but might be best understood as ... responding to a heterogeneous configuration of elements (including ideologies that are residual, as well as currently dominant).

A brief overview of the policy process in respect of 16-19 education will serve to illuminate this further. Young and Leney (1997) have identified three distinct periods of development in respect of the 16-19 curriculum that preceded the current reforms.

The first of these covers the period between 1951 (the inception of A Levels) and 1979, since when, following Callaghan’s 1976 Ruskin speech, governments have 
increasingly intervened in the 'secret garden' of the curriculum. This period was characterised by an acceptance at the level of policy making that A Levels were the most suitable qualification at this level (e.g. the 1959 Crowther Report), and various failed attempts to reform them from the bottom up, for example through the work of the Schools Council.

The second period, 1979-1991, is more interesting. According to Young and Leney (1997) three major features emerged from this period: the increasing resistance of the A Level system to change, and the notion that it represented some form of 'gold standard'; the tendency noted previously towards the incremental changes described by Young (1998); and an increasing polarisation of debate.

The final period between 1991 and the election of the Labour government in 1997 is one of dynamic conservatism and reactive policies, as according to Lawton (1994), the cultural restorationists gained the upper hand over the industrial trainers. There are two strands evident in this period. First, successive Secretaries of State for Education grappled with the problems caused by the inability of the current system to cope with high rates of unemployment and rising student participation post-16. Second, we can see a number of policy initiatives, which reversed the incremental reforms of the previous decade (in particular modular syllabi and coursework), and which moved the system away from the increasingly articulated notions of a unified framework, emerging in the writings of the likes of Finegold et al (1991). They include the 1991 White Paper (DfE 1991), which established the three-track system, with A Levels being offered alongside GNVQ and NVQ. This, according to Hodgson and Spours (1997: 11), 
clearly demonstrated the government's explicit aim of restricting access to A Levels and developing a clear vocational alternative for those who wished to participate in full-time post-sixteen study.

Continued problems following the establishment of the three track system led to further incremental change in the form of the Dearing (1996), Capey (1995) and Beaumont (1995) reviews of education from 16-19. The corollary of such policy development was what Hodgson and Spours (1997: 7) have described as a 'drifting, reactive system', unable to adequately cope with the demands faced by it. The conclusions published by Dearing did little to dispel these problems, predicated as they were on an epistemological assumption that knowledge could be divided into applied and academic tracks, and relying on the continuation of the A Level as the key concept underpinning 16-19 qualifications. In the words of Young and Leney (1997: 72), writing in response to Dearing, 'the real background still is, and always has been the academic track'. This has been viewed as the 'gold standard'; the essentialist notion that 'there is some internally consistent standard among A Levels, and that this standard is sufficiently recognizable to allow discrimination between what is and what is not that standard' (Bloomer 1997: 47).

The Labour government from 1997 is marked by both continuities and discontinuities with this policy trajectory. These will be described in due course, but first it is necessary to briefly summarise some key features of New Labour's education policy. First one can identify a set of concerns underpinning Labour policy which view education both as 'a means of emancipation in itself and as an arena of public policy action which is fundamental to egalitarian strategies' (Hodgson and Spours 1999: 10). This is evident in the policies concerned with widening access and tackling exclusion, 
notably the setting up of Education Action Zones (Cole 1998; Hodgson and Spours 1999).

A second feature of Labour policy is what Hodgson and Spours (1999: 133) have described as 'New Labour's preoccupation with educational standards'. This is clearly manifested through policies to raise standards, such as the literacy and numeracy strategies in compulsory education (Power and Whitty 1999), but also interestingly with the maintenance of existing standards where they are perceived to be good already. This latter tendency would seem to be the case with the A Level 'gold standard'

A third strand of New Labour's education policy that is very evident in the Curriculum 2000 initiative, would seem to be an inherent conservatism. Curriculum 2000 represents a de-radicalisation, when compared with the pre-government policy paper Aiming Higher (Labour Party 1996b). This latter paper advocated a move towards a unified framework, and a more fundamental structural overhaul of the 1419 curriculum than that which emerged post-election in Qualifying for Success (DfEE 1997), and subsequent publications. There are a number of possible reasons for this phenomenon. They include the legacy of nearly twenty years of Tory rule; according to Young and Spours (1998: 86), the incoming administration was 'heavily constrained by Conservative dogmatism', and the continued emphasis on A Levels, on voluntarism and upon external modes of assessment, is indicative of this. A second reason may lie in the much-touted inherent caution of the Labour government. Bloomer (1997: 185) has referred to the 'culture of answerism': a short-term preoccupation with opinion polls that has been alleged to constrain policy making, and a tendency to keep 'a close eye on the opinions of certain groups of voters' (Power and Whitty 1999: 22). These may be apt observations, given the 'political sensitivity 
of A Levels' (Hodgson and Spours 1999: 109). It is interesting to note that the British Baccalaureate seems to be back on the agenda, perhaps spurred on by the grading crisis of the summer of 2002. The Conservative Party has called for its adoption in place of A Levels (e.g. Woodward 2002a); such root and branch reform would replace the 'gold standard', something unthinkable within the last Conservative government. Moreover the British Baccalaureate is clearly also on Labour's policy agenda, for example as evidenced by Estelle Morris’s statement that the 16-18 curriculum could ‘over time ... become a sort of baccalaureate’ (quoted by Woodward 2002b).

Within this complex context, Curriculum 2000 has emerged as a key plank of New Labour's education reform programme. As previously indicated there are a number of areas of both continuity and discontinuity with previous policy. Continuities include a continued commitment to the retention of $A$ Levels as the cornerstone of 14-19 education, and to a voluntarist and elective provision. Discontinuities seem on the surface to include a new commitment to breadth through the extension of Key Skills to all advanced level provision. They exist also through the establishment of the new AS Level qualifications in year 12, and though the apparent erosion of the academicvocational dichotomy via the introduction of smaller units of study and the accompanying exhortations for students to mix-and-match qualifications. As stated in Qualifying for Success (DfEE 1997: 6):

We want to encourage learners to take broader, but coherent programmes of study, including the Key Skills. Too many have narrowed down their studies at too early an age. In particular we want to see more young people of all abilities taking the opportunity to broaden their studies by combining general (academic) studies with more vocational options. 
It is this latter issue, which is the concern of this paper. There are a number of questions to be addressed. These include:

- To what extent have schools broadened their provision in response to Curriculum 2000?

- Has the retention of $A$ Levels as the lynch pin of the system impacted on the government's aim of increasing breadth?

- How have prevailing cultures, histories of provision and epistemological traditions within schools affected the extent to which provision has been broadened?

The next section of this paper addresses these questions in the light of the emerging evidence from schools.

\section{CURRICULUM 2000: HAS IT INCREASED BREADTH?}

The preamble to Qualifying for Success (DfEE 1997: 3) stated unequivocally that the initiative was intended to 'broaden A Levels'. The emerging evidence suggests that this has not occurred, or certainly not to the extent envisaged by the government. This is at least in part acknowledged by the government, albeit with some qualification. The 2002 Green Paper (DfESa 2002: 10) referred to the 'acknowledged difficulties last summer' but stressed that' the reforms are now working well'.

The situation may be more serious. The research outlined in the following section of the paper draws attention to problems encountered in the first round of AS Level examinations (Year 12) in 2001, and follows this up with a look at the same schools a year later after the completion of the A2 Level (Year 13) exams by the first cohort of students to progress through Curriculum 2000. Problems include the tendency amongst some students to reduce their breadth of study, and high drop out rates in 
some cases, contrary to the stated aims of increasing participation and improving retention (Hargreaves 2001a; Hodgson and Spours 2001). Moreover the most recent round of exams in 2002 has been accompanied by stories in the press of similar phenomena. There have been tales of increased workload for students (e.g. Coll 2002), and a reported corollary of this has been a haemorrhage of students from courses and extra curricular activities (e.g. McVeigh 2002).

In effect Curriculum 2000 may not have broadened provision at this level, and moreover has resulted in some quite interesting unintended consequences that have actually worked against the stated aims of the curriculum planners. These issues will be examined in the next section of this paper. Whilst this analysis draws upon the reviews carried out by the IoE/Nuffield research project (Hodgson and Spours 2000; Spours et al 2000; Savory et al 2001; Hodgson et al 2001; Hodgson and Spours 2001) and by QCA (Hargreaves 2001a; 2001b), I will also, as previously indicated, utilise analysis of my own findings.

This study, The impact of Curriculum 2000 in schools, was conducted in three secondary schools in the north of England. Pseudonyms are used throughout to protect the identity of respondents. The schools chosen as case studies are very different to each other in terms of intake and even educational philosophy. Nevertheless there were a number of common trends, and these trends seem to mirror the findings of other reviews of Curriculum 2000. The three schools are as follows:

- Hillfoot School. This is a large to medium sized co-educational school, serving a relatively prosperous suburb of a large city. The Sixth Form at the school is large, and there has traditionally been an emphasis on A Level provision, as opposed to vocational qualifications 
- Streamside Girls’ High School. This small single-sex grammar school has a strong academic tradition, and no history of vocational education or Key Skills.

- City View High School. This very large co-educational high school serves a mixed (in socio-economic terms) catchment area. Its enormous Sixth Form (over 400 students) has a strong tradition of vocational provision, as well as offering a wide range of $A$ Level courses.

The initial purpose of the study was to ascertain and explore teacher and student attitudes towards the Curriculum 2000 initiative at a time when teachers had recently completed the first year of teaching, and when the first cohort of students had completed their AS Level exams. The study was exploratory in nature, and designed to produce preliminary insights into the implementation of Curriculum 2000 in particular contexts. The major part of the research (taking place in the Summer and Autumn of 2001) was devoted to a series of taped and transcribed semi-structured interviews in each school with senior managers, heads of sixth form and heads of department and other teachers in the curricular areas of History and Geography. A small focus group of students was interviewed in each of the schools. I subsequently (in December 2002) supplemented the first round of interviews with a single interview in each school with the Head of Sixth Form to investigate how reactions to Curriculum 2000 had developed since the preliminary interviews. Interviews were designed to discover and articulate the meanings that teachers and managers gave to this major curriculum change, as such meanings help to shape the real world practices in schools. I was especially interested in the extent to which teachers assimilate change into their pre-existing schemata, how these change in response to centrally initiated reform, and particularly the ways in which existing teacher attitudes and 
school sub-cultures might hinder or facilitate the implementation of the new curriculum. Thus the major focus was on the collection and analysis of qualitative data, although some analysis of quantitative data took place, including figures for subject choices and retention as a means of confirming some of the claims made by teachers, for instance in respect of student retention on courses. Research was not focused solely on the issue of breadth; other issues that came to light included the burdens of workload and assessment on both staff and students. However, for the purposes of this paper, these latter issues will only be dealt with insofar as they directly concern the issue of breadth.

\section{IMPACT ON TEACHING}

Spours et al (2000: 4) warned that the 'reforms might not achieve the aim of genuinely broadening student programmes by developing new capacities'. This prediction seems to have been fulfilled, as the initiative has been plagued by problems concerning implementation. Such problems may result from teacher failure to implement the reforms effectively, either through lack of will or lack of capacity. However if this is the case, the voluntarist nature of the reforms, and the lack of implementation support must also bear some of the blame for this. To some degree it is clear that implementation problems are due to the structure of Curriculum 2000. Some of these problems need to be analysed as they have a direct bearing on the issue of breadth.

The issue of support for the schools and teachers was given prominence by many respondents in the first round of interviews, and seems to lie at the heart of any perceived failure to broaden provision through the new curriculum. Complaints included the lateness of INSET and support material, and the low quality and paucity of this when it finally arrived. Students complained that teachers did not know what 
they were doing. Teachers complained that they had no clear idea how or what to teach, especially in terms of depth of coverage. One teacher reflected the views of most in saying,

The exemplar material... the sort of stuff we were getting bore no resemblance to the questions that were being set in the exams (interview with Deputy Head at City View High School, 2001).

Teachers consequently felt that they had to cover all angles, the consequence being over-teaching of syllabi, and corresponding stress on both teachers and students. In the words of one Geography teacher,

The pupils as a result have become severely overloaded, not just in within each subject area, but because they have an increasing number of subjects in which they're expected to perform to an equal standard. And part of that is down to the nature of each individual curriculum itself, but it's also due to the new structure. Teachers themselves still have a reluctance to teach to a lower level than they have in the past, and so therefore err on the side of caution either developing their schemes or work to the highest possible standard, possibly at previous A Level standard as was expected of Lower $6^{\text {th }}$ (interview with Geography teacher at Hillfoot School, 2001).

These sorts of responses have also emerged in the reviews completed by the IoE/Nuffield team (Hodgson et al 2001) and Hargreaves (2001a). A direct corollary of this seems to be overcrowding of course content and a concomitant move to didactic teaching by some teachers, and a 'climate of cramming' (Hargreaves 2001a: 3), a trend also mirrored in my study. According to one teacher: 
I am more teacher-led because I want to get through the content by January ... I don't feel I did as much group work or pair work as under the old A Level (interview with History teacher at City View High School, 2001).

I do not intend in the context of this paper to address the problematic nature and usage of terms like depth and breadth. However at a basic level, it is clear from analysis of the language used by the teachers interviewed that many of them see the new AS Levels as representing a watering down of standards, when compared with previous provision. Most teachers talked of lowering standards and less depth, rather than in terms of reducing content without threatening depth of study. Such teachers tended to associate content with depth, and see the new syllabi as a threat to deeply entrenched modes of practice, which have evolved over many years of teaching A Level courses. Problems have been exacerbated by the fact that many of the new syllabi are content heavy. While all of the schools surveyed had timetabled an equivalent slot per week per subject as previously, the need to prepare students for exams early in the summer term meant in effect less time to teach the same content as previously. Such reluctance, for whatever reasons, to let go of the depth (or at least content heavy approach) associated by teachers with the former A Level syllabi is an interesting phenomenon that seems to be crucial in understanding why an initiative designed to broaden the curriculum has had in some cases the opposite effect.

It seems likely that these problems will become mitigated with time, as teachers become accustomed to the new syllabi, and as guidance improves. Indeed there is emerging evidence of this in the second interview stage of my study. One Head of Sixth Form remarked, 
I think the staff now are getting a better idea of what the level is. Their concern is still the short amount of time that they have to teach it in... It was the depth that they were going to that was the problem not that there was too much in the syllabuses. It was in their interpretation of the syllabuses and when you start to see some of the exemplary material, particular things from coursework coming from the exam board, you start to realise that this is a different level (interview with Head of Sixth Form at Hillfoot School, 2002).

\section{IMPACT ON LEARNERS}

Workload proved to be a major issue for students in the early days, although this has not always been seen as a negative thing; City View High School reported at both stages of the study that the extra workload involved with Curriculum 2000 had actually improved the work ethos of the lower sixth (a finding echoed by Hargreaves 2001a). Nevertheless concerns were expressed about the negative impact of workload by both staff and students at all the schools surveyed. One issue encountered in all of the schools researched concerned timetabling. To summarise what has been previously stated, all of the schools had continued to timetable the same amount of time per subject as in previous years. Moreover, subject teachers were attempting to teach similar levels of content as before, but with effectively only two and a half terms available instead of the traditional three due to the new tier of exams. However under the new arrangements, students were being encouraged to take four or even five subjects at AS Level, as opposed to the traditional three. The net result of this has been A Level courses, forced into less time, at a time when students have to do an extra subject, and negotiate an extra tier of assessment. 
(We are) very concerned about the implications for workload of the students (interview with Deputy Head at Streamside Girls' High School, 2001).

Added to this has been the attempt to 'bolt on' key skills to the programme for each student. The collection of portfolio evidence has been a major commitment for many students. It is in the issue of workload that the impact of the implementation of Curriculum 2000 starts to become apparent. Two of the schools reported in 2001 that many students dropped subjects as a result of the stress caused by workload:

Some of them got really tired, and they were so tired that after Christmas they picked up all kinds of illnesses.... We had a report back from a doctor, and he said that the worst number of girls who have ever gone to him for tranquillisers has been this year with our lower sixth .... We have never had so many students leaving Year 12, it is very worrying, because obviously we are funded in the $6^{\text {th }}$ Form by our numbers, not at the minute by the courses that we take (interview with Head of Sixth Form at Streamside Girls' High School, 2001).

Again, this is an issue that may be expected to improve with time as the reforms bed in, and indeed this has been the case to some extent in two of the schools surveyed. The third school, Streamside Girls’ High continues to experience problems, as a substantial number of students are dropping courses, typically doing three AS Levels and then only two A Levels; a less broad curriculum in other words than they would have experienced typically under the old system! This is clearly not a workload issue; the Head of Sixth Form (interview with Head of Sixth Form at Streamside Girls' High School, 2002) stated that these students now have too much time on their hands. 
However it could be a problem of perception stemming from the serious workload problems experienced by students the previous year.

Another area for concern is the tendency reported in 2001 by two of schools for enrichment activities such as community service to disappear from the programmes of many students. The clear perception of teachers was that stress caused by heavy student workloads, particularly in the case of the more conscientious students, was the factor causing this.

The other thing that was suffering was the voluntary activities. They were not as willing to take on other aspects of helping the school or the Duke of Edinburgh's award (interview with the Head of $6^{\text {th }}$ Form at Streamside Girls' High School, 2001)

A lot of students who would normally get involved in a lot more things, charity fundraising, community service, are coming to me and saying, 'I just can't do this, you know, I really want to, but I just can't (interview with the Head of $6^{\text {th }}$ Form at Hillfoot School, 2001)

Streamside Girls’ High School reported in 2002 that enrichment activities had made a come back following the reductions in workload experienced by many students, but in the case of Hillfoot School there has been a continued decline in extra-curricular activities, including the demise of a thriving Amnesty International group.

Key Skills were intended to be one of the main tools for ensuring breadth in the new curriculum. Here again we see structural problems leading inexorably to problems of implementation, exacerbated by the qualifications being given low priority and resources in some cases. In two of the schools researched, there was a common perception that this aspect of Curriculum 2000 had not taken root, with many students 
not gaining any Key Skills Qualifications, and one of these schools has subsequently dropped them altogether. In the third school, which had a long tradition of vocational provision, fewer problems were reported. Teachers were more upbeat about this aspect of Curriculum 2000, although even here the Head of Sixth Form admitted that fewer than $20 \%$ of students are taking Key Skills courses (interview with Head of Sixth Form at City View High School, 2002). The full picture is gloomy in respect of this aspect of Curriculum 2000. There was a widespread view among teachers and students in all three schools, reported during both stages of the study, that the Key Skills are too hard, especially in IT and Application of Number. There has been no or little time allocated for portfolio development in the schools surveyed. One teacher admitted that she did not understand Key Skills, and other teachers pointed to the logistical nightmare involved in assessing them. Teachers highlighted the lack of sample material and general guidance. One Head of Sixth Form admitted that the Application of Number portfolio for the whole cohort had been failed, despite the school having a very high academic record. This, in her view, has had a major impact on the way in which Curriculum 2000 in its entirety has come to be viewed:

So in the long run the girls have not actually achieved any IT, they've not achieved any Application of Number, and although the majority of them have actually got some Communication, that's coloured the whole feeling towards the whole of Curriculum 2000 exam (interview with Head of Sixth Form at Streamside Girls' High School, 2001)

If such experiences were found to be commonplace in English schools, then one would be forced to concur with the recommendation of Hodgson et al (2001: 2) that the success of Key Skills will have to depend on less congestion generally at A/AS Level, so that 'staff and advanced level students have the time and energy to develop 
key skills as part of their programmes of study'. Moreover, this congestion would have to be eased further by reducing the assessment burden within the Key Skills themselves, as identified by Hargreaves (2001a). Unless these things happen, Key Skills will not become established, they will not improve breadth, and their failure will impact negatively on the whole initiative.

\section{BREADTH}

A key issue that has emerged from my study is the clear tension that exists between the stated aims of broadening the curriculum, and the reluctance of teachers to let go of previously taught A Level content in the face of the voluntarist nature of the reforms. Qualifying for Success (DfEE 1997) acknowledges the tensions that exist between ensuring depth of study, while stating the need for more breadth needed in the current system. Indeed this is nothing new; 'broadening A Levels is a fine slogan that has a forty year history' (Young and Spours 1998: 86). The AS Levels for year 12, and the introduction of Key Skills were seen a being the answer to this problem. However, if my findings are mirrored elsewhere, and the problems reported by the schools are systemic rather than being merely those of implementation, there must be doubts as to whether Curriculum 2000 can succeed in providing the breadth desired. That this has not happened is hardly surprising. Young (1998: 124), writing before the implementation of the new curriculum, pointed out that 'unless it can be shown that breadth enhances specialist study, it will always be seen as being at the price of depth and therefore associated with low standards'. It is the voluntarist and elective nature of Curriculum 2000 that ensures that implementation remains problematic in terms of increasing breadth, and that these metaphorical assumptions remain unchallenged. Thus implementation is hampered at least in part by structural factors. 
Furthermore the evidence from my research shows that in some schools Curriculum 2000 is perceived to be reducing breadth. The demise of enrichment activities in some schools is part of this picture, as is the fact that many students are not actually doing more subjects by the time they have dropped one (or as in the case of the 2002 AS cohort at Streamside Girls High School, some are doing less). Furthermore there is little evidence, at least inititially, that Curriculum 2000 is encouaraging students to mix and match different types of subject (e.g. science and arts) any more than previously where students are allowed free choice:

Also students aren't necessarily choosing the breadth in terms of choosing contrasting subjects, they seem to be choosing very similar subjects (interview with Head of Sixth Form Hillfoot School, 2001).

The IoE/Nuffield research team has been very critical of the voluntarist and elective of Curriculum 2000 since its inception. Indeed this follows a long tradition of criticism of this aspect of the A Level curriculum. The 'flawed philosophy' (Bloomer 1997: 24) of voluntarism has led to a situation where the narrowness of A Level study has in many cases been exacerbated by 'bizarre combinations' (Young 1998: 118) of subjects; this has certainly not helped ensure breadth of study. Curriculum 2000 has done little to prevent these trends. Two of the schools in my sample were reluctant to specify what students will study, perhaps feeling that they would run the risk of losing students to competitors in the education quasi-market. Where one school in my sample had bucked this voluntarist and elective trend, and restricted student choice to ensure that all students took a range of subjects from across the curriculum, this proved to be unpopular with many students, the school reporting at both stages of the study that it had lost some students to local colleges and schools (interview with Head of Sixth Form at Streamside Girls' High School 2001 and 2002). As with other aspects of 
Curriculum 2000, this seems to be improving slightly as schools and students become used to the reforms. Hillfoot School (interview with Head of Sixth Form at Hillfoot School, 2002) reported in the second stage of the study that more students were mixing and matching than previously (although numbers remained low, especially in the case of 'academic' students). According to one teacher at City View High School, (some students) use the AS system very creatively, so we had kids picking up extra AS' in year 13...That came as quite a surprise... Second thing is we've had an increase of take of kids picking up the odd vocational AS in year 13 and that's been really valuable, so for example....about 20 or so kids, have picked up leisure and recreation AVCE which can be done as a 1 year full A' Level (interview with Head of Sixth Form at City View High School, 2002).

The message emerging from this research is that some students, especially those who might have struggled with the traditional A Levels, were benefiting from the flexibility extended to them by Curriculum 2000, but that the majority of students are pursuing similar course profiles as those who came before them; in other words Curriculum 2000 has not broadened their curriculum. Moreover it seems as if the voluntarist aspect of Curriculum 2000 is here to stay, following the Hargreaves reports (2001a; 2001b) and the Green Paper (DfESa 2002). Hodgson and Spours (2001: 20) concur:

At the moment it appears that the realisation of the principles of Curriculum 2000 has been well and truly handed back to schools and colleges. The Government appears to banking on institutions and colleges to translate their underlying commitment to breadth and flexibility into advice and guidance for students and their parents, which will take forward the Curriculum 2000 agenda... This is a risky 
strategy for 2001/2, particularly following a year when schools, colleges and students have had such a bruising experience of the reforms.

If Curriculum 2000 fails in its stated aims of broadening the curriculum, then the retention of the traditional A Level must bear a good deal of the responsibility. It is likely that by failing to reform at the fundamental level of the infrastructure of the curriculum, by simply making 'adjustments' (Hodgson and Spours 2000: 5), the government has ensured that the 'historical debris' (Bloomer 1997: 41) of A Levels, with their emphasis on the narrow and specialised study of separate and unrelated subjects, will dominate the teaching of the new curriculum. As Bloomer (1997: 15) points out,

The most obvious impediment to A Level is that any permutation of three subject specific elements from the universe of knowledge is bound to result in an incomplete curriculum even if judged by the most minimal criteria.

\section{CONCLUSION}

The recent Hargreaves review of Curriculum 2000 states that 'there is overwhelming support in schools and colleges for the principles of Curriculum 2000' (Hargreaves 2001a: 1), a finding at least partially confirmed, even in the face of the grading crisis, by the more recent Tomlinson Report (Tomlinson 2002). According to the former report, students in particular like the notion of breadth, and many teachers believe that this has been a long overdue reform. Such sentiments were also expressed by many of the teachers and students interviewed at the three schools that constituted my study. 
However despite this support in principle, there have been a number of very serious reservations expressed relating to implementation, including issues of breadth. There was agreement amongst reviewers (Hargreaves 2001; Hodgson and Spours 2001) prior to the summer 2002 assessment problems that talk of crisis is misleading, although even at this stage there was some divergence of opinion. The former was largely accepting of the structure of the new curriculum, and sought to frame the problems as those of implementation, which will disappear with time as familiarity with Curriculum 2000 increases. On the other hand, the latter was more critical, blaming the structure of the new curriculum for the problems encountered. The available evidence suggests that this latter perspective may be the more valid: while there are inevitably teething problems, which become less problematic as the reforms bed in, it seems as if the structure of Curriculum 2000 is responsible for many of the problems. The evidence paints a picture of teachers over-teaching the new AS syllabi, and while this can be attributed in part to implementation issues, a share of the blame must also be apportioned to the syllabi being too crowded, and to the failure of the reforms to challenge teacher assumptions about the nature of Sixth Form study (thanks largely to the retention of A Levels); it points to assessment (especially in terms of Key Skills) being too onerous, with corresponding high teacher and student workload and stress. In some cases this has damaged retention and ironically has impacted negatively on the expressed aim of broadening provision at this level. The grading crisis has indeed constituted a crisis for the system, even if it is merely a crisis in perception fuelled by media interest. This may serve as the catalyst for further structural reform in the long-term, as suggested by some of the proposals in the subsequent Tomlinson (2002) report, and by ministerial comment (e.g. DfES 2002b). 
Young (1998) has employed a useful typology, which can be used for analysis of the implementation of Curriculum 2000. He distinguishes between intrinsic logics and institutional logics. The former are to do with the aims and purposes of the policy makers; in the case of Curriculum 2000 a major aim was to broaden provision while retaining the standards associated with A Level study. The latter are concerned with the sorts of factors that exert an influence on curriculum development at the level of the institution (e.g. the tradition of the school, and the life histories [Goodson 1994] of the teachers involved with implementation).

It is evident from the evidence seen that the intrinsic logics of Curriculum 2000 have exerted an effect on the perceptions of schools. The enthusiastic approach of many schools to this initiative was clear at the outset. According to Spours et al (2000: 2), schools and colleges broadly support the principles behind the Curriculum 2000 reforms. There is widespread support for students studying more subjects and integrating key skills into their study programmes.

Comments made by teachers within my study also indicate that many welcomed the reforms. This is evident within the structural arrangements made by schools. The introduction of Key Skills programmes, and in one case the tailoring of the Sixth Form options blocks to ensure that students mixed and matched arts subjects with sciences, are notable examples of schools entering thus into the spirit of Curriculum 2000. However in clear tension with this is the reluctance of some teachers to alter their approach to teaching A Level given the powerful messages about the 'gold standard' of the A Level itself. 
Nevertheless it is equally clear that a powerful effect has been exerted by the institutional logics, especially the factors involving teachers. As argued by Hargreaves (1994: 69),

Teachers do not merely deliver the curriculum. They develop it, define it, and reinterpret it. It is what teachers think, what teachers believe and what teachers do at the level of the classroom that ultimately shapes the learning that young people get.

The powerful institutional logics that have affected this reform include the prior tradition of study. For instance City View High School, that has a tradition of offering Key Skills as part of vocational programmes, seems to have integrated them relatively successfully into its A Level programmes (albeit with a limited student uptake). Conversely, Hillfoot School and Streamside Girls' High School (both schools with academic traditions, high achieving pupils and a lack of such experience) seem to have been in some case less effective in this respect. These findings may be transferable to other schools of similar type. Another example concerns the depth of $A$ Level study. In the schools where A Level has a strong tradition, it is clear that teachers have struggled to modify their teaching to incorporate the extra breadth required. This in turn has had knock on effects, and in many cases has resulted in students reverting to a more traditional model of two to four complementary A Levels, without Key Skills. This is perhaps indicative of general trends associated with centre-periphery dissemination of curriculum innovation, as noted by Goodson (1994: 13) with 'frenetic activity in the foreground (tending to) obscure some of the deeper continuities in the background'. Such logics inevitably act as a barrier to the reforms succeeding. Such a barrier becomes stronger when one considers the structural and extra-institutional constraints under which the implementation of the reform is 
occurring. These include the voluntarist and elective nature of Curriculum 2000, and the lack of effective support and tight timeframes for implementation.

On a parting note, it is interesting to reflect on whether Curriculum 2000 represents a final point for the time being in terms of 16-19 curriculum development. Will we see moves towards a 14-19 framework, for example, or further steps towards a unified framework as envisaged by the likes of Michael Young (Young 1998)? The emerging political rhetoric from Ministers suggests that the British Baccalaureate remains firmly on the agenda, despite the fact that Labour backtracked from its original proposals for post-sixteen curriculum reform (Labour Party 1996b). Or will A Levels continue to dominate the scene? Will we, in the words of Bloomer (1997: 173) continue to see 'yesterday's answers' stifling 'the questions for tomorrow'?

\section{ACKNOWLEDGEMENT}

I wish to extend my thanks to Richard Edwards for advice freely given during the drafting of this paper, and to Jeremy Higham and David Yeomans for their support during the research project, upon which the paper draws.

\section{REFERENCES}

BALL, S. (1990) Politics and Policy Making in Education: explanations in policy sociology (London, Routledge)

BALL, S. (1999) Labour, Learning and the Economy: a 'policy sociology' perspective’ Cambridge Journal of Education, 29(2), pp. 195-206

BEAUMONT, G. (1995) Review of 100 NVQs and SVQs: a report submitted to the DfEE (London, DfEE) 
BLOOMER, M. (1997) Curriculum-Making in Post-16 Education: the social conditions of studentship (London, Routledge)

CAPEY, J. (1995) GNVQ Assessment review (London, NCVQ)

COLL, J. (2002) A higher level of pressure, The Guardian, $16^{\text {th }}$ July 2002. Available at http://education.guardian.co.uk/aslevels/story/0,10495,756262,00.html

CURTIS, P (2002) Curriculum 2000 created too much work, says report, The Guardian, $26^{\text {th }}$ June 2002. Available at http://www.guardian.co.uk/education/further/story/0,5500,744333,00.html

DALE, R. (1999) Specifying globalization effects on national policy: a focus on the mechanisms, Journal of Education Policy, 14(1), pp. 1-17

DEARING, R. (1996) Review of qualifications for 16-19 year olds : full report (London, School Curriculum and Assessment Authority)

DfE (1991) Education and Training for the $21^{\text {st }}$ Century (London, HMSO)

DES (1988) Advancing A Levels : report of a Committee appointed by the Secretary of State of Education and Science and the Secretary of State for Wales (London, HMSO)

DfEE (1997) Qualifying for Success: a consultation paper on the future of post-16 qualifications (London, DfEE)

DfES (2002a) Education and Skills 14-19: extending opportunities, raising standards: summary. Available at http://www.dfes.gov.uk/14-19greenpaper/

DfES (2002b) Statement by Charles Clarke: Inquiry into A Level standards ( $3^{\text {rd }}$ December). Available at http://www.dfes.gov.uk/alevelsinquiry/docs/3Decstatement.doc 
FINEGOLD, D., KEEP, E., MILIBRAND, D., RAFFE, D., SPOURS, K. AND YOUNG, M. (1991) A British Baccalaureate: overcoming divisions between education and training (London, Institute for Public Policy Research)

GOODSON, I. F. (1994) Studying Curriculum (Buckingham, Open University Press)

GREEN, A. (1999) Education and globalization in Europe and East Asia: convergent and divergent trends, Journal of Education Policy, 14(1), pp. 55-71

HARGREAVES, A (1983) The Politics of Administrative Convenience, in: J. AHIER AND M. FLUDE (Eds.) Contemporary Education Policy (Beckenham, Croom Helm)

HARGREAVES, A. (1994) Changing Teachers, Changing Times: teachers' work and culture in the post-modern age (London, Cassell)

HARGREAVES, D. (2001a) Review of Curriculum 2000: QCA's report on Phase One (London, QCA)

HARGREAVES, D. (2001b) Review of Curriculum 2000: QCA's report on Phase Two (London, QCA)

HODGSON, A. AND SPOURS, K. (1997) From the 1991 White Paper to the Dearing Report: a conceptual and historical framework for the 1990s, in: A. HODGSON AND K. SPOURS (Eds.) Dearing and Beyond: 14-19 qualifications, frameworks and system (London, Kogan Page)

HODGSON, A. AND SPOURS, K. (1999) New Labour's Education Agenda: issues and policies for education and training from 14+ (London, Kogan Page)

HODGSON, A. AND SPOURS, K. (2000) Qualifying for Success: towards a framework of understanding (London, IOE) 
HODGSON, A. AND SPOURS, K. (2001) Evaluating Stage 1 of the Hargreaves Review of Curriculum 2000: an analysis of teachers' and students' views and the future of the reform process (London, IOE)

HODGSON, A, SPOURS, K. AND SAVORY, C. (2001) Improving the 'Use' and 'Exchange' Value of Key Skills. Debating the role of the Key Skills qualification within Curriculum 2000 (London, IOE)

LABOUR PARTY (1996a) Lifelong Learning (Labour Party, London)

LABOUR PARTY (1996b) Aiming Higher: Labour's proposals for the reform of the 14-19 curriculum (London, Labour Party)

LAWTON, D. (1994) The Tory Mind of Education, 1979-1994 (London, Falmer Press)

MCVEIGH, T. (2002) Pupils quit in exams panic, in: The Guardian, 23 ${ }^{\text {rd }}$ June 2002. Available at http://www.guardian.co.uk/education/schools/story/0,5500,742413,00.html

QCA (1999) Curriculum 2000 (London, QCA)

POWER, S. AND WHITTY, G. (1999) New Labour's education policy: first, second or third way?, Journal of Education Policy, 14(5), pp. 535-546

PRIESTLEY, M. (2002) Global discourses and national reconstruction: the impact of globalization on curriculum policy, The Curriculum Journal, 13(1), pp. 87104

REICH, R. (1991). Why the rich are getting richer and the poor, poorer, in: A. H. HALSEY, H. LAUDER, P. BROWN AND A. S. WELLS (Eds.) (1997) Education, Culture, Economy and Society (Oxford, Oxford University Press) 
REICH, R. (1992) The work of nations: preparing ourselves for $21^{\text {st }}$ century capitalism (London, Simon and Schuster)

SCHON, D (1971) Beyond the Stable State: public and private learning in a changing society (London, Maurice Temple Smith Ltd)

SPOURS, K., SAVORY, C. AND HODGSON, A. (2000) Current Advanced level Provision in England and Early Institutional Responses to Curriculum 2000 (London, IOE)

SAVORY, C., HODGSON, A. AND SPOURS, K. (2001) Planning and Implementing Curriculum 2000: institutional approaches (London, IOE)

TOMLINSON, M. (2002) Inquiry into A Level Standards (London: DfES)

WOODWARD, W. (2002a). Tories look at replacing A-Levels with baccalaureate, in: The Guardian, $27^{\text {th }}$ August. Available at http://education.guardian.co.uk/schools/story/0,5500,781146,00.html

WOODWARD, W. (2002b). A Levels may get another overhaul, in: The Guardian, $23^{\text {rd }}$ September. Available at http://education.guardian.co.uk/alevels2002/story/0,12321,797077,00.html

YOUNG, M. D. F. (1998) The Curriculum of the Future: from the 'new sociology of education' to a critical theory of learning (London, Falmer Press)

YOUNG, M. D. F. AND LENEY, T. (1996) From A Levels to an Advanced Level Curriculum of the Future, in: A. HODGSON AND K. SPOURS (Eds.) Dearing and Beyond: 14-19 qualifications, frameworks and systems. (London, Kogan Page) 
YOUNG, M. D. F. AND SPOURS, K. (1998) 14-19 Education: legacy, opportunities and challenges, Oxford Review of Education, 24(2), pp. 83-97 